\title{
Modified Devine Exclusion for Unresectable Distal Gastric Cancer in Symptomatic Patients
}

\author{
María Carmen Fernández-Moreno ${ }^{a} \quad$ Roberto Martí-Obiol ${ }^{a}$ \\ Fernando López ${ }^{a, b}$ Joaquín Ortega ${ }^{a, b}$ \\ ${ }^{a}$ Department of Surgery, Clinical University Hospital, Valencia, Spain; ${ }^{b}$ Department of \\ Surgery, University of Valencia, Valencia, Spain
}

\section{Keywords}

Gastroenterostomy · Stomach neoplasm · Gastric outlet obstruction · Palliative care

\begin{abstract}
Background: In patients with outlet obstruction syndrome and/or severe anemia secondary to unresectable gastric cancer (GC), partial stomach-partitioning gastrojejunostomy, or modified Devine exclusion, is a surgical alternative. Methods: A retrospective study was conducted on patients with unresectable distal GC treated with modified Devine exclusion as palliative surgery between February 2005 and December 2015. It consisted of a series of 10 patients with outlet obstruction syndrome and/or severe anemia. The outcomes of this technique were based on oral tolerance, blood transfusions, postoperative complications, and survival. Results: Early oral tolerance and a low rate of blood transfusions were observed postoperatively. There was no postoperative mortality and a very low complication rate without anastomotic leakage. Median survival was 9 months. Conclusions: Partial stomach-partitioning gastrojejunostomy is a safe procedure for unresectable GC which can improve the quality of life of these patients.




\section{Case Reports in Gastroenterology}

Case Rep Gastroenterol 2017;11:9-16

(c) 2017 The Author(s). Published by S. Karger AG, Basel www.karger.com/crg

Fernández-Moreno et al : Modified Devine Exclusion for Unresectable Distal Gastric Cancer in Symptomatic Patients

\section{Introduction}

Despite many advances in the diagnosis of gastric cancer (GC), a high percentage of patients are in advanced stages at diagnosis and are not susceptible to curative treatment. Treatment is then usually palliative and should provide symptomatic relief without adding morbidity, improve quality of life, and increase survival if possible. Furthermore, complications such as bleeding, obstruction, and perforation can arise in patients with locally advanced GC. The therapeutic options for palliative care include resective or derivative surgery, endoscopic therapies (prosthesis, photodynamic therapy, laser, dilatations, ...), chemotherapy (CT), radiotherapy, or intratumoral injections [1]. The treatment decision must be individualized considering the characteristics of the tumor, the symptoms, the general health of the patient (performance status), and life expectancy.

Modified Devine exclusion consists of a gastrojejunostomy after partial transection of the stomach proximal to the antral tumor. This technique theoretically offers advantages over other alternative palliative therapies $[2,3]$.

The aim of this study was to assess the feasibility, safety, and efficacy of modified Devine exclusion as a method for palliation in patients with unresectable distal GC.

\section{Patients and Methods}

Between February 2005 and December 2015, 10 patients underwent modified Devine exclusion for symptomatic unresectable GC. All patient data were collected prospectively within a standardized and auditable database including patient demographics, ECOG performance status, symptoms, tumor characteristics, length of and complications during postoperative stay, postoperative morbidity according to the Clavien-Dindo classification, and other postoperative factors such as blood transfusions, resumption of oral intake, and global survival. Data were analyzed retrospectively.

An intraoperative evaluation of the tumor is carried out by the surgeon confirming unresectability. Modified Devine exclusion, or partial stomach-partitioning gastrojejunostomy, is performed in these cases of unresectable disease. The criteria for unresectability are based on extensive involvement of the mesentery root, large vessels (except for the splenic artery), liver or bile duct, pancreatic head, or duodenum, which would require a cephalic duodenal pancreatectomy, and cases with expected R2 resection or patients with functional contraindication to major resection.

\section{Surgical Procedure}

The gastric partition was performed $3-5 \mathrm{~cm}$ proximal to the lesion in the large curvature using a linear cutting stapler and preserving a narrow tunnel in the small gastric curve. Subsequently, a retrocolic, anisoperistaltic gastrojejunostomy was performed between the posterior wall of the proximal stomach and the antimesenteric edge of a proximal loop of the jejunum, about $20 \mathrm{~cm}$ from the ligament of Treitz. One procedure was carried out laparoscopically. 


\section{Case Reports in Gastroenterology}

Case Rep Gastroenterol 2017;11:9-16

(c) 2017 The Author(s). Published by S. Karger AG, Basel www.karger.com/crg

Fernández-Moreno et al : Modified Devine Exclusion for Unresectable Distal Gastric Cancer in Symptomatic Patients

\section{Results}

A total of 10 patients were included; 6 were male (60\%) and 4 were female (40\%), with a mean age of 69 years (range, 48-89) in the total sample - 66 years (range, 51-80) for males and 74 years (range, 49-89) for females. All patients had an ECOG performance status of 0,1 , or 2 . Gastric outlet obstruction symptoms were predominant in 6 cases, and 4 patients presented tumor-related bleeding with need of repeat blood transfusions.

According to the Lauren classification, $60 \%$ of tumors in this series were adenocarcinomas of intestinal type, $30 \%$ were of diffuse type, and $10 \%$ were of mixed type. Localization of the tumor was antrum-pylorus in all of them. Table 1 shows the patients' clinical and pathologic characteristics.

The average hospital stay was 13 days (range, 7-20). Postoperative complications occurred in 2 patients. Based on the classification of Clavien-Dindo, one of them had a grade I by superficial surgical wound infection. Another patient had grade IIIb because he suffered a perforation in the sigma where an intraoperative biopsy of a tumoral implant was carried out. This patient was treated by urgent Hartmann's procedure. None of the patients presented anastomotic leakage or dehiscence of gastric suture lines, and none died during the postoperative period.

In cases where surgery was performed for gastric obstruction, all patients were discharged with tolerance of oral intake to soft or full diet, with a Gastric Outlet Obstruction Scoring System (GOOSS) score [4] of 2-3. During follow-up there was no recurrence of obstructive symptoms in any of them.

In patients undergoing surgery for bleeding, an improvement was observed in average hemoglobin levels, which increased from $7.5 \mathrm{~g} / \mathrm{dL}$ preoperatively to $9.8 \mathrm{~g} / \mathrm{dL}$ in the first postoperative month.

The median survival was 9 months. No patient received CT after surgery, and only 2 were in neoadjuvant $\mathrm{CT}$ at the time of the intervention.

\section{Discussion}

There is no gold standard procedure in palliative care for unresectable GC, and the choice of treatment in these cases depends on the characteristics of the patient and the tumor. Thus, many times palliative care is needed when the tumor has spread to neighboring organs and is unresectable or metastatic, and other times because of the comorbidities in inoperable patients. The aims of palliative care should be to alleviate associated symptoms, improve quality of life, and increase survival if possible. Nevertheless, the prognosis of these patients is poor. The outcomes of palliative solutions must be known to surgeons so that they can make the best choice for the patient. Based on symptoms and performance status or Karnofsky score, we can offer various possibilities of treatment: resective or bypass surgery, endoscopic therapy (dilatations, Nd:YAG laser, photodynamic therapy, or antroduodenal stents), and palliative chemoradiotherapy [5-7].

Conventionally, surgical resection was considered the best palliative option, although in cases of advanced unresectable distal GC it is not realistic to expect increased survival, and 


\section{Case Reports in Gastroenterology}

Case Rep Gastroenterol 2017;11:9-16

DOI: $10.1159 / 00045275$

(c) 2017 The Author(s). Published by S. Karger AG, Base www.karger.com/crg

Fernández-Moreno et al:: Modified Devine Exclusion for Unresectable Distal Gastric Cancer in Symptomatic Patients

only a low percentage of patients are currently associated with a better clinical course [810].

A multidisciplinary committee is desirable in order to assess every case individually. In our study, symptomatic GC was associated with carcinomatosis in $30 \%$ of patients, with liver metastases in $30 \%$, and with spread to neighboring organs in $40 \%$. Two of them were in CT treatment at the moment of palliative surgery, and all of them had an ECOG performance status of 0,1 , or 2 , reasons why the palliative option was bypass surgery. Regarding the symptomatology, $60 \%$ of patients suffered from gastric outlet obstruction, and in $40 \%$ bleeding predominated. Bypass surgery enabled these patients to ingest food, and among the cases of bleeding tumor, only 1 patient needed a new blood transfusion.

In palliative bypass surgery conventional gastrojejunostomy (Fig. 1a), described by Wölfer in 1881, has been the standard of treatment in unresectable GC. However, occasionally this surgery is not completely effective and patients experience no palliation of their symptoms. Among its disadvantages are a delay in gastric emptying, the risk of tumor bleeding as it continues in contact with food, and the risk of new gastric outlet obstruction if the tumor grows [11]. Laparoscopic gastrojejunostomy shows advantages over open procedure, with a decreased need of analgesia, shorter hospital stay, and lower postoperative morbidity [12].

The Devine exclusion procedure (Fig. 1b), introduced in 1925 for the treatment of duodenal ulcer, was an effective alternative, but could not be used in all cases of locally advanced GC. It consists in a complete transection of the stomach and a gastroenterostomy; when the antrum is completely occluded, a probe is needed in the distal remnant for decompression and to prevent perforation. In addition, when the minor curvature is infiltrated, performing this technique is not possible.

Kaminishi et al. [13] described in 1997 a surgical procedure with a modification of Devine exclusion (Fig. 1c). It consists in a partial separation of the stomach with a gastrojejunostomy in the proximal gastric remnant. The authors reported less tumoral bleeding, less delay in gastric emptying, and better and more complete oral intake than with conventional gastrojejunostomy. Unlike Devine exclusion, their procedure allows posterior endoscopic assessment of the tumoral lesion. It can also be carried out laparoscopically, with good postoperative outcomes [14].

Bile reflux is one of the disadvantages of this technique, which is why Suzuki et al. [15] suggest doing a gastrojejunostomy with Roux-en-Y reconstruction (Fig. 1d). Several studies indicate that this anastomosis minimizes the delay in gastric emptying and reduces hospital stay [16]. However, in our study, Roux-en-Y anastomosis was not performed, and all patients kept oral intake until death without symptoms added. This is why we consider that it is not mandatory to do 2 anastomoses on these kind of patients. Finally, the surgical procedure proposed by Oida et al. [17] consists in a partial gastric separation with an additional triangular resection of the proximal gastric remnant in order to achieve better gastric emptying (Fig. 2).

Gastroduodenal stents are another alternative for the palliative treatment of gastric outlet obstruction. The procedure is able to solve obstruction faster and has a clinical success rate of $87 \%$; however, its stent-related complications rates are $>20 \%$ (bleeding, perforation, migration, reobstruction) [18]. Better results for expandable stents are found in patients with shorter life expectancy or with contraindication to surgery $[5,19]$. 
Morbidity associated with palliative surgery is low, as our study shows. In order to minimize this morbidity, laparoscopic access is an option to consider in these patients. Compared to open gastrointestinal anastomosis, the laparoscopic approach has revealed lower morbidity and mortality, shorter hospital stay, lower number of blood transfusions, and faster gastrointestinal function recovery. However, the risk of conversion forces proper patient selection in these advanced cases [20].

Retrospective studies comparing conventional gastrojejunostomy and partial gastric separation have indicated an increase in survival and a low bleeding rate in support of partial gastric separation. Thus, Kwon and Lee [21] reported a median survival of 209 days. In our study we obtained a median survival of 270 days. Hence, although our study was retrospective and included a a low number of patients, we can conclude that partial stomachpartitioning gastrojejunostomy is a feasible, safe, and effective technique in patients with unresectable distal GC for treatment of gastric obstruction as well as bleeding tumors.

\section{Statement of Ethics}

All procedures followed were in accordance with the ethical standards of the responsible committee on human experimentation (institutional and national) and with the Helsinki Declaration of 1964 and later versions. Informed consent was obtained from all patients for being included in the study.

\section{Disclosure Statement}

The authors declare that they have no conflict of interest.

\section{References}

1 Sano T, Aiko T: New Japanese classifications and treatment guidelines for gastric cancer: revision concepts and major revised points. Gastric Cancer 2011;14:97-100.

-2 Fernández OA, Parreño-Manchado F, García-Plaza A: Partial stomach partitioning gastrojejunostomy in the treatment of the malignant gastric outlet obstruction (in Spanish). Cir Cir 2015;83:386-392.

3 Kwok SPY, Chung SC, Griffin SM, Li AK: Devine exclusion for unresectable carcinoma of the stomach. $\mathrm{Br}$ J Surg 1991;78:684-685.

$\checkmark 4$ Adler DG, Baron TH: Endoscopic palliation of malignant gastric outlet obstruction using self-expanding metal stents: experience in 36 patients. Am J Gastroenterol 2002;97:72-78.

5 Miller A, Schwaitzberg S: Surgical and endoscopic options for benign and malignant gastric outlet obstruction. Curr Surg Rep 2014;2:48.

6 Caglar E, Dobrucali A: Self-expandable metallic stent placement in the palliative treatment of malignant obstruction of gastric outlet and duodenum. Clin Endosc 2013;46:59-64.

7 Jeurnink SM, van Eijck CH, Steyerberg EW, Kuipers EJ, Siersema PD: Stent versus gastrojejunostomy for the palliation of gastric outlet obstruction: a systematic review. BMC Gastroenterol 2007;7:18.

$>8$ Okumura Y, Yamashita H, Aikou S, Yagi K, Yamagata Y, Nishida M, Mori K, Nomura S, Kitayama J, Watanabe T, Seto Y: Palliative distal gastrectomy offers no survival benefit over gastrojejunostomy for gastric cancer with outlet obstruction: retrospective analysis of an 11-year experience. World J Surg Oncol 2014;12:364. 


\section{Case Reports in Gastroenterology}

Fernández-Moreno et al:: Modified Devine Exclusion for Unresectable Distal Gastric Cancer in Symptomatic Patients

$>9$

Waddell T, Verheij M, Allum W, Cunningham D, Cervantes A, Arnold D; European Society for Medical Oncology (ESMO); European Society of Surgical Oncology (ESSO); European Society of Radiotherapy and Oncology (ESTRO): Gastric cancer: ESMO-ESSO-ESTRO Clinical Practice Guidelines for diagnosis, treatment and follow-up. Ann Oncol 2013;24(suppl 6):vi57-vi63.

Yang K, Liu K, Zhang WH, Lu ZH, Chen XZ, Chen XL, Zhou ZG, Hu JK: The value of palliative gastrectomy for gastric cancer patients with intraoperatively proven peritoneal seeding. Medicine (Baltimore) 2015;94:e1051.

Doberneck RC, Berndt GA: Delayed gastric emptying after palliative gastrojejunostomy for carcinoma of the pancreas. Arch Surg 1987;122:827-829.

Al-Rashedy M, Dadibhai M, Shareif A, Khandelwal MI, Ballester P, Abid G, McCloy RF, Ammori BJ: Laparoscopic gastric bypass for gastric outlet obstruction is associated with smoother, faster recovery and shorter hospital stay compared with open surgery. J Hepatobiliary Pancreat Surg 2005;12:474478.

Kaminishi M, Yamaguchi H, Shimizu N, Nomura S, Yoshikawa A, Hashimoto M, Sakai S, Oohara T: Stomach-partitioning gastrojejunostomy for unresectable gastric carcinoma. Arch Surg 1997;132:184187.

Arrangoiz R, Papavasiliou P, Singla S, Siripurapu V, Li T, Watson JC, Hoffman JP, Farma JM: Partial stomach-partitioning gastrojejunostomy and the success of this procedure in terms of palliation. Am J Surg 2013;206:333-339.

5 Suzuki O, Shichinohe T, Yano T, Okamura K, Hazama K, Hirano S, Kondo S: Laparoscopic modified Devine exclusion gastrojejunostomy as a palliative surgery to relieve malignant pyloroduodenal obstruction by unresectable cancer. Am J Surg 2007;194:416-418.

Szymanski D, Durczynski A, Nowicki M, Strzelczyk J: Gastrojejunostomy in patients with unresectable pancreatic head cancer - the use of Roux loop significantly shortens the hospital length of stay. World J Gastroenterol 2013;19:8321-8325.

Oida T, Mimatsu K, Kawasaki A, Kano H, Kuboi Y, Amano S: Modified Devine exclusion with vertical stomach reconstruction for gastric outlet obstruction: a novel technique. J Gastrointest Surg 2009;13: 1226-1232.

van Halsema EE, Rauws EA, Fockens P, van Hooft JE: Self-expandable metal stents for malignant gastric outlet obstruction: a pooled analysis of prospective literature. World J Gastroenterol 2015;21:1246812481.

Jeurnink SM, Steyerberg EW, van Hooft JE, van Eijck CH, Schwartz MP, Vleggaar FP, Kuipers EJ, Siersema PD; Dutch SUSTENT Study Group: Surgical gastrojejunostomy or endoscopic stent placement for the palliation of malignant gastric outlet obstruction (SUSTENT study): a multicenter randomized trial. Gastrointest Endosc 2010;71:490-499.

Alam TA, Baines M, Parker MC: The management of gastric outlet obstruction secondary to inoperable cancer. Surg Endosc 2003;17:320-323.

Kwon SJ, Lee HG: Gastric partitioning gastrojejunostomy in unresectable distal gastric cancer patients. World J Surg 2004;28:365-368. 


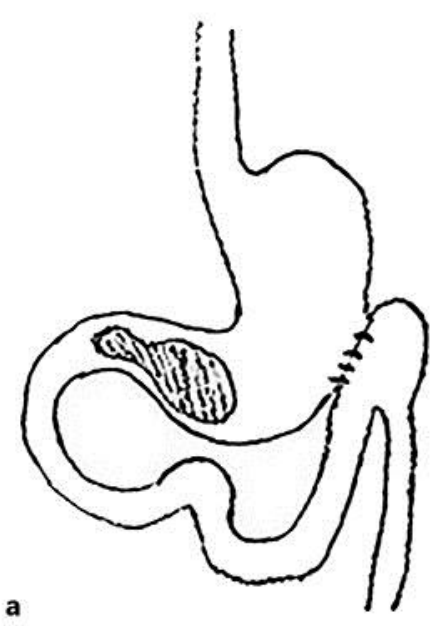

a

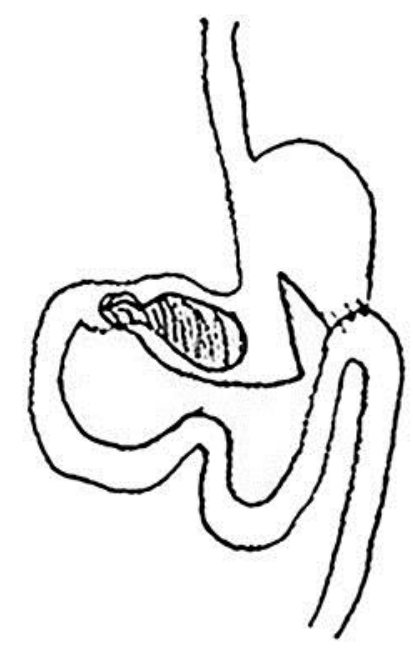

c
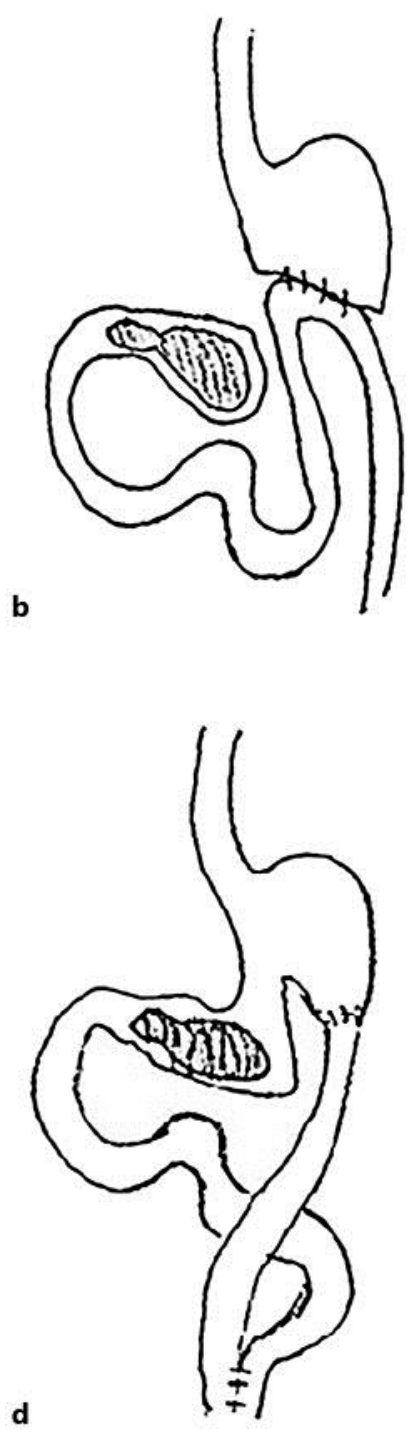

Fig. 1. Various types of bypass surgery in patients with unresectable distal gastric cancer. a Conventional gastrojejunostomy. b Devine exclusion procedure. c Modified Devine exclusion. d Modified Devine exclusion with Roux-en-Y reconstruction. 


\begin{tabular}{ll|l} 
Case Reports in & \begin{tabular}{l} 
Case Rep Gastroenterol 2017;11:9-16 \\
\cline { 2 - 3 } Gastroenterology
\end{tabular} & $\begin{array}{l}\text { D } 2017 \text { The Author(s). Published by S. Karger AG, Basel } \\
\text { www.karger.com/crg }\end{array}$ \\
\hline & $\begin{array}{l}\text { Fernández-Moreno et al.: Modified Devine Exclusion for Unresectable Distal Gastric } \\
\text { Cancer in Symptomatic Patients }\end{array}$
\end{tabular}

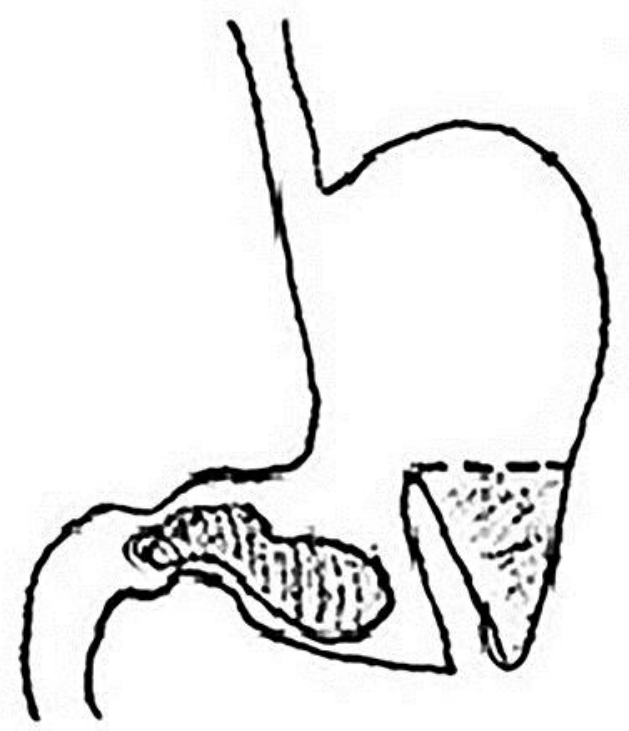

Fig. 2. Added resection proposed by Oida et al. [17].

Table 1. Clinical and pathologic characteristics of the patients

\section{Disease stage}

Hepatic metastases, $n \quad 1$

Peritoneal carcinomatosis, $n \quad 2$

Hepatic metastases + carcinomatosis, $n \quad 1$

T4b invading

Pancreatic head, $n \quad 4$

Transverse mesocolon, $n \quad 1$

Hepatic segment V + gallbladder, $n \quad 1$

\section{Clinical expression}

Upper gastrointestinal bleeding, $n \quad 4$

Average pre-/postoperative hemoglobin, g/dL $\quad 7.5 / 9.8$

Gastric outlet obstruction, $n$

6

$n$, number of cases. 